\title{
Mathematical model for supply chain design with time postponement
}

\section{Marcos Wagner Jesus Servare Junior ${ }^{1}$, Patricia Alcântara Cardoso², Marta Monteiro da Costa $\mathrm{Cruz}^{3}$, Marcia Helena Moreira Paiva ${ }^{4}$}

\author{
1Programa de Pós-Graduação em Engenharia Civil - Transportes, UFES, marcoswjunior@gmail.com \\ 2Programa de Pós-Graduação em Engenharia Civil - Transportes, UFES, patricia.cardoso@ufes.br \\ 3Programa de Pós-Graduação em Engenharia Civil - Transportes, UFES, marta.cruz@ufes.br \\ 4Programa de Pós-Graduação em Engenharia Elétrica, UFES, marcia.paiva@ufes.br
}

\section{Recebido:}

13 de fevereiro de 2017

Aceito para publicação:

6 de julho de 2018

Publicado:

31 de dezembro de 2018

Editor de área:

Claudio Barbieri da Cunha

\section{Keywords:}

Supply Chain Design,

Time postponement,

Mathematical Model.

\section{Palavras-chaves:}

Projeto de cadeia de suprimentos, Postergação de Tempo,

Modelo Matemático.

DOI:10.14295/transportes.v26i4.1324

\begin{abstract}
Designing a supply chain is a major strategic issue due to its impact on efficiency and responsiveness. The design becomes more complex when the goal is to reduce distribution costs and use the time postponement in the supply chain. The mathematical models currently studied in the literature consider various actors involved in the network. However, in real problems there are different combinations of actors, creating own transportation flows and increasing the complexity of a supply chain. This paper proposes a model for designing supply chains with time postponement from a mixed integer non-linear programming formulation to minimize the total costs, considering the transportation, facilities opening and operational costs. The model allows the possibility of a hybrid facility, that is, two kinds of facilities opened in the same place, an important opportunity to saving costs. Some sets of instances were simulated to find the optimal solution of that model and analyze the supply chain behavior in different instances sizes. These scenarios were solved by a commercial solver and its performance was assessed. The model presents feasibility of use for small and medium-sized instances with enough computing time to aid in management decision making.
\end{abstract}

\section{RESUMO}

Projetar cadeia de suprimentos é uma importante decisão estratégica e seu impacto influencia diretamente na eficiência e no nível de serviço. O projeto se torna mais complexo quando o objetivo é minimizar o custo de distribuição e utilizar a postergação de tempo na cadeia de suprimentos. Os modelos matemáticos atualmente estudados na literatura de cadeia de suprimentos consideram vários atores. Entretanto, em problemas reais existem diferentes combinações desses atores, criando fluxos próprios de transportes e aumentando a complexidade da cadeia de suprimentos. Este artigo propõe um modelo matemático para projetar a cadeia de suprimentos com postergação de tempo a partir da programação não linear inteira mista para minimizar o custo total, considerando os custos de transportes, abertura de instalações e operacionais. 0 modelo permite a possibilidade de uma instalação híbrida, ou seja, dois tipos de instalações abertas no mesmo local, sendo uma importante oportunidade de redução de custos. Diferentes conjuntos de instâncias foram simulados para buscar a solução ótima e analisar o comportamento da cadeia de suprimentos em diferentes tamanhos de cenários, os quais foram resolvidos usando um solver comercial e suas performances foram estudadas. O modelo proposto apresenta viabilidade em seu uso para instâncias pequenas e médias com tempo computacional suficiente para auxílio no processo de tomada de decisão.

\section{INTRODUCTION}

Decisions regarding product distribution are important strategic issues for most organizations. Specifically, the inventory location problem is a critical component in the supply chain's strate- 
gic management planning. Some important factors such as costs and distances to the points of consumption, as well as the moment that products should move downstream in the supply chain must be considered. The challenge of making the product available in the required place and time is a challenge that must be solved in order to design the best logistics supply chain.

The use of modern tools and technology to assist in this process is observed every moment. Therefore, we need to consider some important factors such as costs and distances to the points of consumption and demand for each of these regions.

Choosing the best supply chain configuration and providing the demand with the product availability in the place and time in which it is required are defiance in this kind of problem. Time postponement is one of the consequences from practice of inventory centralization at a specific point in the supply chain, the inventory could be opened in a supplier or factory (see Figure 1), before sending to following node, if the inventory were opened in the retail will be a different problem type know by speculation principle.

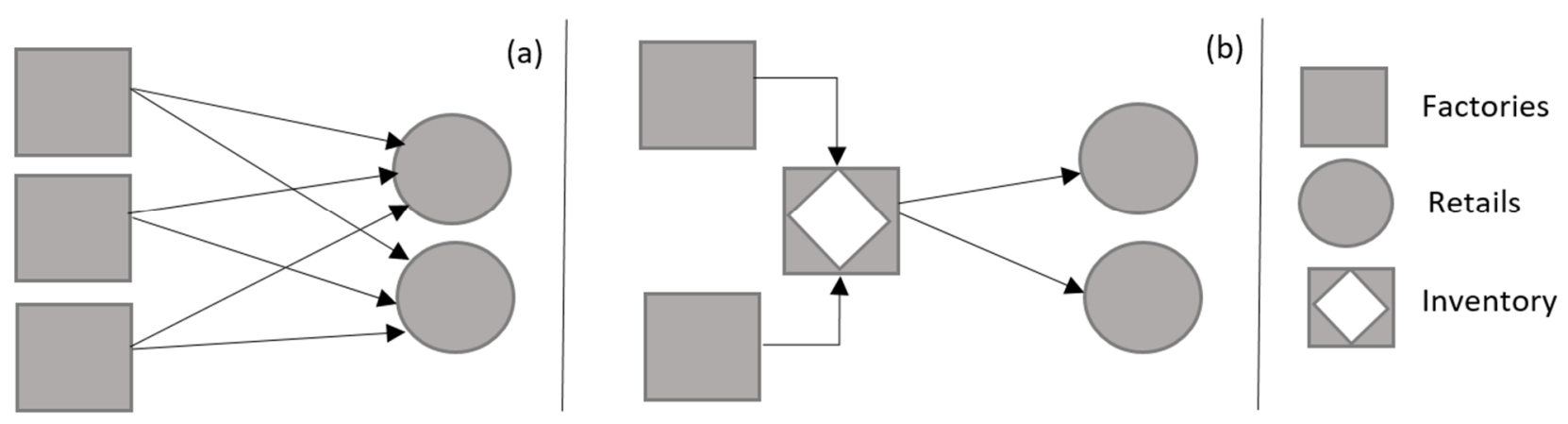

Figure 1. Supply chain without Time Postponement (a) and supply chain with Time Postponement (b)

Time postponement can be defined as the delaying of product movement as late as possible within a physical distribution process (Cardoso, 2002). Researches regarding time postponement cover different areas, such as pharmaceutical industries (Razmi et al., 2013) and auto industry (Nozick and Turnquist, 2001).

Thus, the organizations seek effective ways to rethink their logistical investments. The redefinition of the boundaries of these organizations, their skills, eliminating unnecessary steps and restructuring processes are factors that contribute to this end (Ferreira and Alcantara, 2011).

Inventory policies directly influence the strategic decisions of a company, due to its capacity, transportation decisions, responsiveness, and investments. This characterization may impact the competitiveness of the organization and may promote the minimization of costs and, even, to maximize the responsiveness (Fernandes et al., 2011).

The number of companies that centralize the receiving processes, storage, order picking, packing and shipping has increased (Santos, 2006; Rodrigues and Pizzolato, 2013). The centralization is expected to minimize logistics costs. Other companies and authors are looking for integrated transportation and inventory policies in order to minimize logistic costs (e.g. Peres et al., 2017).

In order to minimize costs and use the time postponement in logistics network some authors [e.g., (Lau and Lau, 1996; Garcia-Dastugue and Lambert, 2007; Çelebi, 2015)] present in the literature different mathematical models that aim to optimize this management process. 
Thus, the use of mathematical modeling to obtain an exact solution for problems of this type contributes to an alternative decision to a business agent.

Different than others, this paper presents a model that allows the inclusion of a hybrid facility to design a supply chain with time postponement (SCDTP) using mixed integer non-linear programming to obtain the minimum total cost.

\section{LITERATURE REVIEW}

The concept of postponement was defined by Alderson (1950) as the ordering of stages of value aggregation in manufacturing and marketing processes. This concept proposes to modify the form, identity, or place of goods occurring at the last possible point in the processes of manufacture and physical distribution.

The most important goal of the principle is to reduce the risks by keeping the products in one place and only changing them when the following echelon makes the order. Postponing the movement of the product was denominated time postponement; on the other hand, the postponement in the product differentiation was denominated form postponement.

Cardoso (2002) points out the relationship between the economies related to the use of safety stock and time postponement. Furthermore, the author highlights the reduction of safety stock as an important advantage of time postponement costs.

Time postponement requires the implementation of specific inventory policies that focus the products on a single point in the distribution channel until the order is placed (Ferreira, 2009). Servare Junior and Cardoso (2016) presented a literature review of SCDTP models to support the development of robust models, which are capable to take into account all logistics costs. These models are classified into four features and their characteristics. For each characteristic a code is proposed (see Table 1).

- Objective: The objective function presented in the paper, that is the main information which the authors want to optimize as minimizing cost or maximizing profit (C), maximizing covering $(\mathrm{Cb})$ and maximizing responsiveness (Res).

- Outputs: The variables used in the development of the mathematical models, each paper presents its variables to optimize the objective function and to be subject to constraints of model, e.g. transportation mode (Md), facility location (L) and product location (LP).

- Modeling: In this section the model was classified according to the kind of mathematical programming, i.e. dynamic (DP), mixed integer non-linear (MINLP), mixed integer linear (MILP) or stochastic mixed integer programming (SMIP).

- Problem Definition: The main models characteristics as the how many periods and products the model consider to plan, the quantity of facilities that could be opened, if the vehicle and facility have a fixed capacity value.

These models range from simple single-product and single-period uncapacitated facility models [e.g. (Nozick and Turnquist, 2001)] to complex multi-product multi-period multi-mode models [e.g. (Kutanoglu and Lohiya, 2008)] and they are usually aimed at determining minimum cost or maximum profit system design.

Because of the increasing importance of network responsiveness in supply chain management, this has recently been considered as a significant additional objective for multi-objective supply chain network design [e.g. (Gaur and Ravindran, 2006)]. 
The solution methods for each model are then presented by Servare Junior and Cardoso (2016) in Table 2.

Table 1: Classification of Supply Chain Design with Time Postponement (Servare Junior and Cardoso, 2016).

\begin{tabular}{|c|c|c|}
\hline \multicolumn{2}{|c|}{ Feature and Classification } & \multirow{2}{*}{$\begin{array}{l}\text { Code } \\
\text { Res }\end{array}$} \\
\hline \multirow{3}{*}{ Objective } & Max responsiveness & \\
\hline & Min cost/ Max profit & $\mathrm{C}$ \\
\hline & Max Covering & $\mathrm{Cb}$ \\
\hline \multirow{11}{*}{ Outputs } & Inventory & I \\
\hline & Orders amount & Q \\
\hline & Transportation amount & TA \\
\hline & Location & L \\
\hline & Product Location & LP \\
\hline & Replenishment point & PR \\
\hline & Service Time & ST \\
\hline & Transportation Mode & Md \\
\hline & Cost & $\mathrm{Ct}$ \\
\hline & Facility Capacity & $\mathrm{Cp}$ \\
\hline & Demand Satisfaction Quantity & DS \\
\hline \multirow{4}{*}{ Modeling } & Dynamic Programming & DP \\
\hline & Mixed Integer Non-Linear Programming & MINLP \\
\hline & Mixed Integer Linear Programming & MILP \\
\hline & Stochastic Mixed Integer Programming & SMIP \\
\hline \multirow{18}{*}{ Problem Definition } & Period & \\
\hline & Multi-period & $\mathrm{MPr}$ \\
\hline & Single Period & SPr \\
\hline & Numbers of facilities to be opened & \\
\hline & Endogenous (Undetermined) & En \\
\hline & Exogenous (Determined) & Ex \\
\hline & Product & \\
\hline & Single-product & SP \\
\hline & Multi-products & $\mathrm{MP}$ \\
\hline & Flow Capacity & \\
\hline & Uncapacitated & UCF \\
\hline & Capacitated & $\mathrm{CF}$ \\
\hline & Demand & \\
\hline & Stochastic & $S$ \\
\hline & Deterministic & $\mathrm{D}$ \\
\hline & Facility Capacity & \\
\hline & Uncapacitated & UC \\
\hline & Capacitated & $\mathrm{Ca}$ \\
\hline
\end{tabular}


Table 2: Coding of reviewed articles in Supply Chain Design with Time Postponement (Servare Junior and Cardoso, 2016).

\begin{tabular}{|c|c|c|c|c|c|}
\hline Reference Papers & Problem Definition & Modelling & Output & Objectives & $\begin{array}{l}\text { Solution } \\
\text { method }\end{array}$ \\
\hline Lau and Lau (1996) & SPr; En; MP; UCF; UC; D & MINLP & Q & $\mathrm{C}$ & Heuristic \\
\hline Das and Tyagi (1997) & SPr; En; SP; UCF; UC; D & MINLP & TA & $\mathrm{C}$ & Heuristic \\
\hline Eynan (1999) & SPr; En; SP; UCF; UC; S & MILP & I & C & Exact \\
\hline Nozick and Turnquist (2001) & Spr; En; SP; UCF; UC; D & MILP & $\mathrm{TA} ; \mathrm{L}$ & $\mathrm{C}$ & Exact \\
\hline Aviv and Ferdegruen (2001) & Mpr; En; MP; UCF; UC; S & DP & LP & $\mathrm{C}$ & - \\
\hline Gaur and Ravindran (2006) & SPr; En; SP; UCF; Ca; D & MINLP & TA; L; Q; PR & C; Res & Heuristic \\
\hline Garcia-Dastugue and Lambert (2007) & MPr; En; SP; UCF; UC; D & MILP & ST & $\mathrm{C}$ & Exact \\
\hline Kutanoglu and Lohiya (2008) & MPr; En; MP; UCF; UC; D & MINLP & I; Md; DS & $\mathrm{C}$ & Heuristic \\
\hline Razmi et al. (2013) & SPr; Ex; SP; UCF; Ca; S & SMIP & $\mathrm{TA} ; \mathrm{L} ; \mathrm{Ct} ; \mathrm{Cp}$ & $\mathrm{C} ; \mathrm{Cb}$ & Heuristic \\
\hline Çelebi (2015) & MPr; Ex; SP; UCF; Ca; D & MILP & I & $\mathrm{C}$ & GA \\
\hline
\end{tabular}

Lau and Lau (1996) used a Lagrangian multiplication procedure and then applied a heuristic for solving the problem MINLP. The implementation was the Levenberg-Marquardt algorithm, with the subroutine IMSL. From an initial solution to the implementation of heuristics enabled the convergence to the optimal solution in the instances that the authors indicated.

Das and Tiagy (1997) use exact techniques through solvers to achieve the results to a MINLP problem and then select 8 customer areas and 3 facilities in the Southeastern United States, using data from secondary sources. The implementation of the model indicates the degree of centralization of inventory in each proposed scenario. They are suggested and solved 5 scenarios that range among them the features of the model formulation costs.

Applications of Eynan (1999) model had the effect of centralizing inventories, for example, the profit from the adoption of the planning tool.

Nozick and Turnquist (2001) submit weights to balance the objective function according to the scenario of studies and, as a case, the model was applied in an automotive industry case study in the United States. The model was solved with 698 consumers zones, and the scenarios output presented answer with lower cost and greater coverage opening 23 and 64 warehouses, respectively.

Aviv and Ferdegruen (2001) present the mathematical formulation, but do not make use of the model. Several algebraic applications and tests are carried out to simplify the problem.

Gaur and Ravindran (2006) used two commercial solvers for solving the model. In this case, the authors present an algorithm that uses the solvers to perform steps proposed.

García-Dastugue and Lambert (2007) used exact techniques to solve the model in the indicated instances.

Kutanoglu and Lohyia (2008) proposed the model to solve- two cases, the first there was one facility, and the second there were three facilities, with the General Algebraic Modeling System (GAMS) modeling language together with CPLEX for the generated instances.

A pharmaceutical distribution company in Tehran, Iran, was a case study analyzed by Razmi et al. (2013). In their paper, the distribution network has 2 factories, 6 available warehouses and 20 consumer areas. The plants produce, stock, ship and deliver drugs to customers. They implemented the same technique to find the model solution and proposed scenarios. Çelebi (2015) executed a heuristic, the Genetic Algorithm, for solve the model. 
Based on the aforementioned considerations, this work developed a SCDTP model including supply, production, distribution and inventory location in a supply chain and solved it using a commercial solver to find the optimal solution in the instances created.

\section{PROBLEM DEFINITION}

The SCDTP discussed in this paper is a multi-stage logistics network including production, distribution, retails and two possibilities of inventory location, the first appearance is in the 1st level, the suppliers ship their products to this place located in one of the suppliers and the other possibility occurs in the 2 nd level, the inventory will be inside of one of factories. The complete process of the SCDTP under consideration is illustrated in Figure 2.

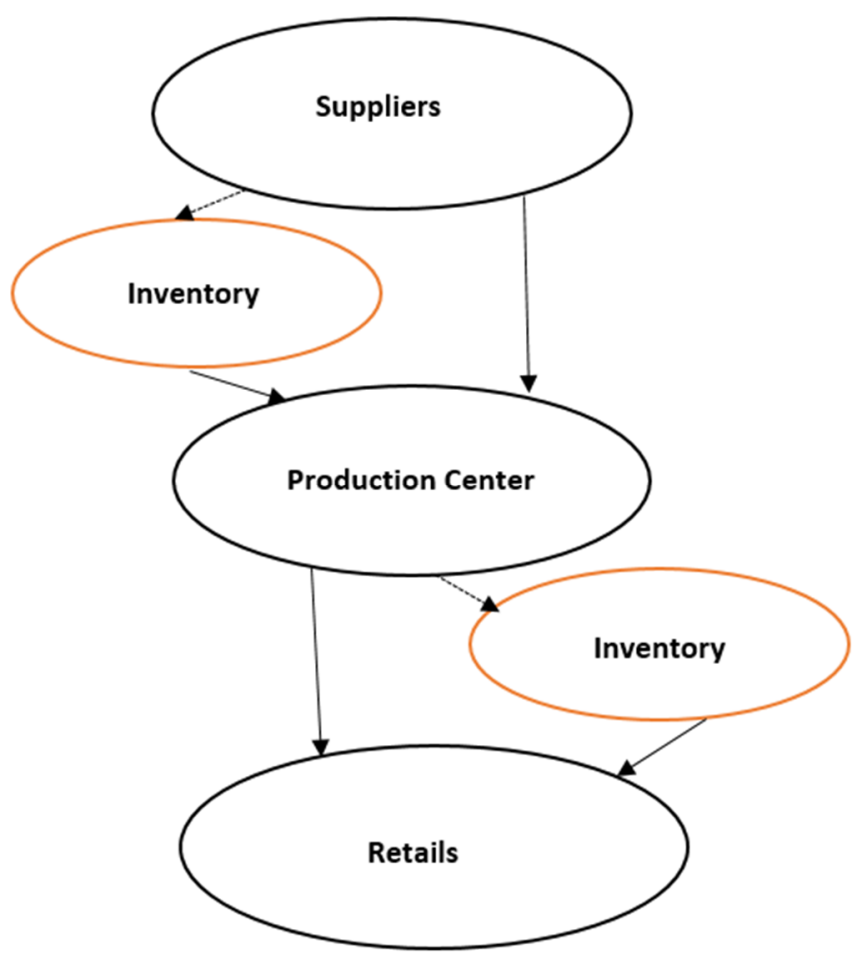

Figure 2. Time postponement process in the studied network

As illustrated in Figure 3, the supplies are shipped from the suppliers to retails through production centers, to use these supplies to produce goods, and inventory located in $1^{\text {st }}$ or $2^{\text {nd }}$ level. Retails and suppliers are assumed to be predetermined and fixed. The supplies are shipped to inventory or production centers and, then, if the supplies were shipped to inventory, they are shipped to production center or if the supplies were shipped to production center the products made in production center are shipped to inventory, this one located in the $2^{\text {nd }}$ level.

As a way to reduce costs, the proposal for this work includes the use of hybrid facilities. These facilities are able to contain two different types of facilities in the same location, saving space and preventing the company from having to buy other spaces. The model will be able to tell the manager which facilities will be combined and present him the best location.

The SCDTP therefore considers a hybrid inventory-production facility whereby both inventory and production centers are established at the same location. The resulting cost saving is reflected in the objective function, which considers both the tradeoff of fixed opening costs of facilities and variable transportation costs. Thus, unlike previous models with hybrid facilities 
(e.g. Pshivaee et al.,2010; Servare Junior et al., 2012), the use of hybrid-collection facilities is a decision variable in the SCDTP model.

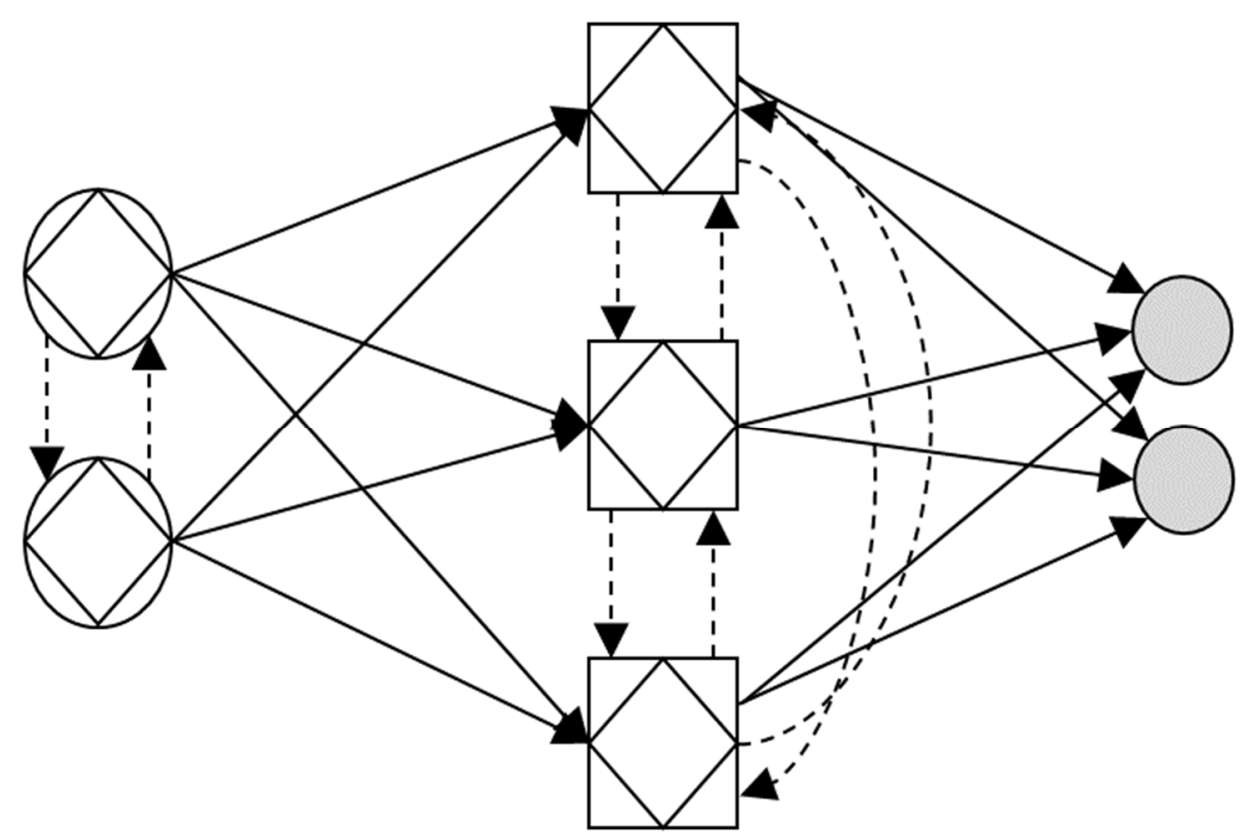

Flow between

different levels

Flow inside the level

Supplier

(1st level)

Factory

(2nd level)

$>$ Inventory

Retail

(3rd level)

Figure 3. A supply chain network with time postponement

With the above situations in mind, the main issues to be addressed by this study are to determine the location and the number of production centers, and the location of the inventory or inventory-product center, that represent the degree of centralization of the network, and also to determine the product flow between the facilities. SCDTP is not a case-based network and because of its generic nature, it can support a variety of industries such as pharmaceutical industries (e.g. Razmi et al., 2013) and auto industry (e.g. Nozick and Turnquist, 2001).

It is important to note that the SCDTP is designed to take network costs into account, such as the variable costs - transportation costs - and the fixed costs - opening and operational costs. According to Table 1, the problem in question can be coded as shown in Table 3.

Table 3: Coding of the problem in question

\begin{tabular}{lllll}
\hline Problem Definition & Modelling & Output & Objectives & Solution method \\
\hline SPr; Ex; SP; UCF; Ca; D & MINLP & I; TA. L; Ct & C & Exact \\
\hline
\end{tabular}

\subsection{Model formulation}

To support the presentation of the proposed mathematical model, we first provide a verbal description of the model as follows.

Minimize costs

$=$ Fixed opening costs - Savings from integrating facilities

+ Transportation Costs + Operationals Costs

Subject to

- satisfying all forward and reverse demands, 
- balancing of flows between nodes,

- capacity constraints,

- logical constraints related to time postponement,

- non-negativity and binary constraints.

The following notation are used in formulation of the model.

Sets

$H: \quad$ Fixed supplier locations $h \in H$

I: $\quad$ Set of potential inventory locations in a supplier $i \in I$

$J: \quad$ Set of potential production center locations $j \in J$

$K: \quad$ Set of potential inventory locations in a production center $k \in K$

$L: \quad$ Set of potential inventory locations in a production center $k \in K$

$E: \quad$ Set of joint potential sites between production centers and inventory

$e \in E, e \subset J, e \subset K$

Parameters

$f_{i}$ : $\quad$ Fixed cost of opening an inventory location $i$ in the $1^{\text {st }}$ level of network

$o_{j}$ : $\quad$ Fixed cost of opening production center $j$.

$p_{k}: \quad$ Fixed cost of opening production center $j$

$f_{e}$ : Fixed saving cost associated with opening inventory location and production center at location $e$

$c a_{h i}$ : Shipping cost per unit of products from supplier $h$ to inventory location $i$

$c b_{i j}$ : Shipping cost per unit of products from inventory location $i$ to production center $j$

$c c_{j k}$ : Shipping cost per unit of products from production center $j$ to inventory location $k$

$c q_{k l}$ : Shipping cost per unit of products from inventory location $k$ to retail $l$

$c r_{h j}$ : $\quad$ Shipping cost per unit of products from supplier $h$ to production center $j$

$c s_{j l}: \quad$ Shipping cost per unit of products from supplier $h$ to production center $j$

$\operatorname{coi}_{i}$ : Operational cost in inventory location $i$

$\operatorname{coj}_{j}$ : Operational cost in production center $j$

$\operatorname{cok}_{k}: \quad$ Operational cost in inventory location $k$

$d_{h}$ : Quantity of products offered by the supplier $h$

$\operatorname{cax}_{i}$ : $\quad$ Capacity for inventory location $i$

$\mathrm{caw}_{j}$ : Capacity for inventory location $i$

cay $_{k}$ : Capacity of inventory location $k$

$\mathrm{cal}_{l}$ : Demand of retail $l$

Variables

$X_{i}$ : $\quad 1$ if an inventory location $i$ is opened in the $1^{\text {st }}$ level of network; 0 otherwise

$W_{j}: \quad 1$ if a production center $j$ is opened; 0 otherwise

$Y_{k}: \quad$ if an inventory location $k$ is opened in the $2^{\text {nd }}$ level of network; 0 otherwise

$A_{h i}$ : $\quad$ Quantity of products shipped from supplier $h$ to inventory location $i$ 
$B_{i j}$ : Quantity of products shipped from inventory location $i$ to production center $j$

$C_{j k}$ : Quantity of products shipped from production center $j$ to inventory location $k$

$Q_{k l}: \quad$ Quantity of products shipped from inventory location $k$ to retail $l$

$R_{h j}$ : Quantity of products shipped from supplier $h$ to production center $j$

$S_{j l}$ : $\quad$ Quantity of products shipped from production center $j$ to retail $l$

The time postponement design problem developed in this work is presented below:

$$
\begin{aligned}
\operatorname{Min} \sum_{i \in I} f_{i} X_{i} & +\sum_{j \in J} o_{j} W_{j}+\sum_{k \in K} p_{k} Y_{k}-\sum_{e \in E} f_{e} Y_{e} W_{e}+\sum_{h \in H} \sum_{i \in I} c a_{h i} A_{h i} \\
& +\sum_{i \in I} \sum_{j \in J} c b_{i j} B_{i j}+\sum_{j \in J} \sum_{k \in K} c c_{j k} C_{j k}+\sum_{k \in K} \sum_{l \in L} c q_{k l} Q_{k l} \\
& +\sum_{h \in H} \sum_{j \in J} c r_{h j} R_{h j}+\sum_{j \in J} \sum_{l \in L} c s_{j l} S_{j l}+\sum_{i \in I} c o i_{i} X_{i}+\sum_{j \in J} c o j_{j} W_{j} \\
& +\sum_{k \in K} \operatorname{cok}_{k} Y_{k}
\end{aligned}
$$

Subject to

$$
\begin{aligned}
& \sum_{i \in I} A_{h i}+\sum_{j \in J} R_{h j}=d_{h} \quad \forall h \in H \\
& \sum_{h \in H} A_{h i}=\sum_{j \in J} B_{i j} \quad \forall i \in I \\
& \sum_{i \in I} B_{i j}+\sum_{h \in H} R_{h j}=\sum_{k \in K} C_{j k}+\sum_{l \in L} S_{j l} \forall j \in J \\
& \sum_{j \in J} C_{j k}=\sum_{l \in L} D_{k l} \quad \forall k \in K \\
& \sum_{h \in H} A_{h i} \leq \operatorname{cax}_{i} X_{i} \quad \forall i \in I \\
& \sum_{j \in J} B_{i j} \leq \operatorname{cax}_{i} X_{i} \quad \forall i \in I \\
& \sum_{i \in I} B_{i j}+\sum_{h \in H} R_{h j} \leq \operatorname{caw}_{j} W_{j} \quad \forall j \in J \\
& \sum_{k \in K} C_{j k}+\sum_{l \in L} S_{j l} \leq \operatorname{caw}_{j} W_{j} \quad \forall j \in J \\
& \sum_{j \in J} C_{j k} \leq \operatorname{cay}_{k} Y_{k} \quad \forall k \in K \\
& \sum_{l \in L} D_{k l} \leq \operatorname{cay}_{k} Y_{k} \quad \forall k \in K \\
& \sum_{k \in K} D_{k l}+\sum_{j \in J} S_{j l} \leq \operatorname{cal}_{l} \quad \forall l \in L
\end{aligned}
$$


$\sum_{i \in I} X_{i}+\sum_{k \in K} Y_{k}=1$

$\sum_{j \in J} R_{h j} \leq\left(1-\sum_{i \in I} X_{i}\right) \cdot d_{h} \quad \forall h \in H$

$\sum_{j \in J} S_{j l} \leq\left(1-\sum_{k \in K} Y_{k}\right) \cdot \operatorname{cal}_{l} \quad \forall l \in L$

$A_{h i}, B_{i j}, C_{i k}, D_{k l}, R_{h j}, S_{j l} \geq 0 \quad \forall i \in I, j \in J, k \in K, h \in H, l \in L$

$X_{i}, W_{j}, Y_{k} \in\{0,1\} \forall i \in I, j \in J, k \in K$

The objective function (1) minimizes the total costs including fixed opening costs, transportation costs and the cost savings associated with integrating inventory location and production centers at the same locations. Constraints (2) ensure that the demands of all production centers are satisfied, shipped directly from suppliers or through the inventory located in the $1^{\text {st }}$ level. The Equations (3) - (5) assure the flow balance at suppliers, inventories, production centers and retails [e.g. Pshivaae et al. (2010), Servare Junior et al. (2012) and Razmi et al. (2013)].

Constraints (8) - (12) are capacity constraints on facilities, which also prohibit the supplies and products from being transferred to facilities that are not opened. If the principle of postponement by Alderson (1950) defines that the inventory can not be located at retail, specifically this case is called by speculation, and as the inventory centralization is a consequence of time postponement, then the Constraint (13) ensure will be opened one inventory in the supply chain in the first or second level of the supply chain (e.g. Das and Tiagy, 1997; Nozick and Turnquist, 2001; Razmi et al., 2013).

If any $X_{i}=1$, the inventory is opened in the first level of supply chain and the products will be not be shipped to an inventory in second level, this condition is assured by Equations (14), otherwise, if the inventory in the second level, the Constraint (15) guarantees that the suppliers ship their products to the inventory opened in that level.

Finally, Constraints (16) and (17) enforce the binary and nonnegativity restrictions on the corresponding decision variables.

The term

$$
\sum_{e \in E} f_{e} Y_{e} W_{e}
$$

in the objective function (1) is non-linear because it involves the multiplication of two binary variables. As Pishvaee et al. (2010) and Servare Junior et al. (2012), in order to avoid the complexity from a MINLP model, the above model is linearized reformulating the objective function as follows and by defining a new variable:

$$
\begin{aligned}
T_{e}=Y_{e} * & W_{e} \\
T_{e}=\{0 ; 1\} & \forall e \in E \\
\operatorname{Min} \sum_{i \in I} f_{i} X_{i} & +\sum_{j \in J} o_{j} W_{j}+\sum_{k \in K} p_{k} Y_{k}-\sum_{e \in E} f_{e} T_{e}+\sum_{h \in H} \sum_{i \in I} c a_{h i} A_{h i} \\
& +\sum_{i \in I} \sum_{j \in J} c b_{i j} B_{i j}+\sum_{j \in J} \sum_{k \in K} c c_{j k} c_{j k}+\sum_{k \in K} \sum_{l \in L} c q_{k l} Q_{k l} \\
& +\sum_{h \in H} \sum_{j \in J} c r_{h j} R_{h j}+\sum_{j \in J} \sum_{l \in L} c S_{j l} S_{j l}+\sum_{i \in I} c o i_{i} X_{i}+\sum_{j \in J} c o j_{j} W_{j} \\
& +\sum c o k_{k} Y_{k}
\end{aligned}
$$


Because the objective function minimizes costs, it has a tendency to put the value of $T_{e}$ variable to 1 . Therefore, we should only prohibit the value of $T_{e}$ to be 1 in three conditions: when both of $Y_{e}$ and $W_{e}$ or one of them is equal to zero. This can be achieved by adding the following constraint to the model:

$2 * T_{e} \leq Y_{e}+W_{e}$

Adding constraints (19) and (21) the model (1) - (17), the objective function (1) may be replaced by (20) making a linear model.

Considering each feature of the models, adding the constraints of them to allow the creation of supply chain design with these actors and with time postponement, the model was developed presenting a new possible combination of participants, besides the possibility of opening a facility (factory) on the second node and the discount associated with this installation is a hybrid facility with the inventory working on it.

\section{COMPUTATIONAL PROCEDURES}

15 different scenarios were created, so that a model of behavior analysis is performed from the increased number of participants in the network. Three groups of instances were produced according to the number of participants in each scenario, the first group Instances 1-5, with a small amount of characters for each type of facility, increasing this amount in instances 6-10 and, further increasing, in instances 11-15. Table 4 shows the test instances.

Also, the column called Group represents the test groups. The Instance column represents all test instances simulated and used. The column H indicates the number of suppliers and column I the number of suppliers that can store the goods originating from other suppliers in each instance.

The columns J and K represent, respectively, the number of production centers in the $2^{\text {nd }}$ level and the amount thereof that can become an inventory too. Lastly, column L shows the number of retails having a product demand.

As a way of observing the behavior of the model, we used the largest number of possible installations as alternatives to open inventory, that is, all the facilities of $1^{\text {st }}$ or $2^{\text {nd }}$ level would be able to be chosen as inventory. Thus, the values of the pairs $H$ and $I$ and $J$ and $K$ were the same. If it is necessary to run the model with different values it is possible, since $I \leq H$ and $K \leq J$.

Table 4: Test problems' sizes

\begin{tabular}{lllll}
\hline Group & Instances & $\boldsymbol{H}$ and $\boldsymbol{I}$ & $\boldsymbol{J}$ and $\boldsymbol{K}$ & $\boldsymbol{L}$ \\
\hline \multirow{4}{*}{1} & 1 & 2 & 3 & 2 \\
& 2 & 8 & 5 & 3 \\
& 3 & 15 & 10 & 5 \\
& 4 & 20 & 15 & 8 \\
& 5 & 35 & 20 & 15 \\
\hline & 6 & 100 & 50 & 30 \\
& 7 & 120 & 100 & 50 \\
& 8 & 150 & 100 & 75 \\
& 9 & 180 & 110 & 90 \\
& 10 & 200 & 125 & 100 \\
\hline
\end{tabular}


Table 4: Test problems' sizes (continue)

\begin{tabular}{lllll}
\hline Group & Instances & $\boldsymbol{H}$ and $\boldsymbol{I}$ & $\boldsymbol{J}$ and $\boldsymbol{K}$ & $\boldsymbol{L}$ \\
\hline & 11 & 300 & 150 & 150 \\
& 12 & 300 & 200 & 120 \\
3 & 13 & 300 & 200 & 150 \\
& 14 & 500 & 400 & 200 \\
& 15 & 750 & 500 & 250 \\
\hline
\end{tabular}

In the absence of actual values for model input parameters, the estimated values were used [See Pshivaae et al. (2010) and Servare Junior et al. (2012)]. Table 5 shows the parameters and ranges of values considered for each one.

Table 5: The values of the parameters used in the test problems

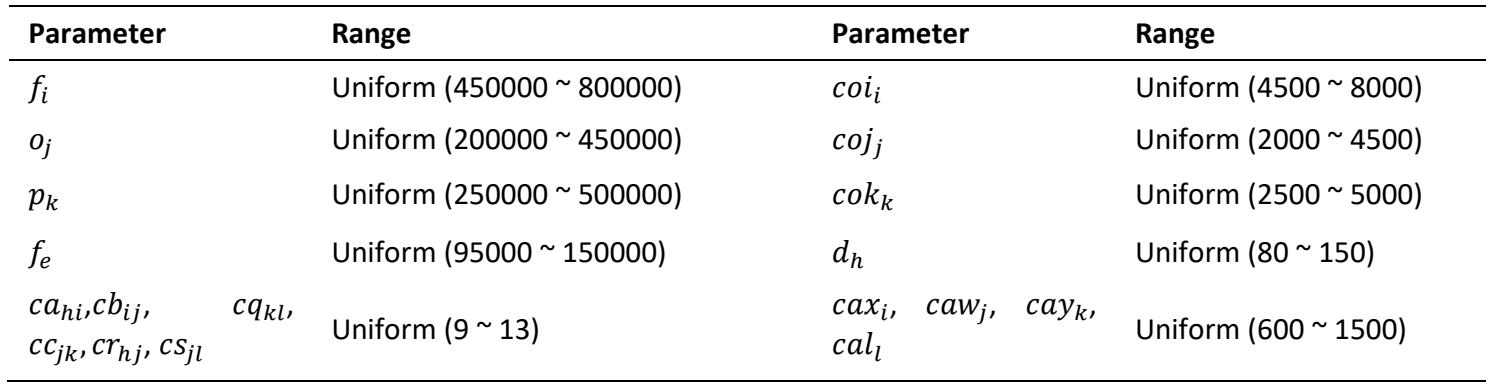

\subsection{Computational Results}

The test instances aforementioned have been implemented in a commercial solver, the CPLEX 12.5 (IBM, 2012). All the tests are carried out on an Intel core i5 $2.50 \mathrm{GHz}$ computer with $4 \mathrm{~GB}$ RAM and results are obtained [See Table 6].

Table 6: Summary of test results

\begin{tabular}{|c|c|c|c|c|}
\hline Group & Instance & Objective Function & Inventory & Time (Seconds) \\
\hline \multirow{5}{*}{1} & 1 & 398436 & $Y_{3}$ & $00: 52$ \\
\hline & 2 & 385852 & $Y_{4}$ & $00: 47$ \\
\hline & 3 & 398442 & $Y_{7}$ & $00: 94$ \\
\hline & 4 & 388141 & $Y_{12}$ & 00:93 \\
\hline & 5 & 427830 & $Y_{6}$ & 01:87 \\
\hline \multirow{5}{*}{2} & 6 & 581892 & $Y_{43}$ & $06: 32$ \\
\hline & 7 & 609047 & $Y_{95}$ & 41:91 \\
\hline & 8 & 655430 & $Y_{11}$ & $52: 29$ \\
\hline & 9 & 703780 & $Y_{59}$ & $51: 66$ \\
\hline & 10 & 757288 & $Y_{17}$ & $87: 57$ \\
\hline \multirow{5}{*}{3} & 11 & 853506 & $Y_{78}$ & $184: 78$ \\
\hline & 12 & 979599 & $Y_{180}$ & $660: 29$ \\
\hline & 13 & 941204 & $Y_{188}$ & $455: 85$ \\
\hline & 14 & - & - & 7491:29* \\
\hline & 15 & - & - & 218:38* \\
\hline
\end{tabular}


After the simulations, we found that it is possible to find model solutions for small and medium-sized. But from the instance \#14 the CPLEX was not able to get the solution for lack of memory.

\subsection{Discussion of the results}

The model solved the instances from 1 to 13 , respecting the constraints that the model is subject to, we also observed that instances 14 and 15 could not be solved due to lack of memory.

The growth of the Objective Function within each instance group is explained by the increase of suppliers and the demand of customers, as well as a greater flow between the facilities. It was also observed that the execution time generally increased as the instances became more complex, resulting in values that exceeded 10 minutes of execution or even being unable to complete the solution processing due to lack of memory.

Although there are times over than 10 minutes are much longer than the processing time of the first tests, it is important to note that it is a satisfactory time for the decision making in a supply chain design.

The explanation for the first event is that for some situations the problem became less costly as facilities were added, the model found a location of opening that generated fewer expenses, determined its openness and directed flows to this point, and the expense avoided for this location covered the of transportation costs that increases as new facilities are added upstream and new demands downstream.

In turn, the computational effort could be reduced according to the processing of the algorithm from CPLEX 12.5 (IBM, 2012) to find a solution for MINLP, once it finds a solution according to the parameters of the algorithm.

As a representation form, according to characteristics presented in Table 5, the schematization of the problem of Instance \#1 is in Figure 3 and the solution found is shown in the Figure 5.

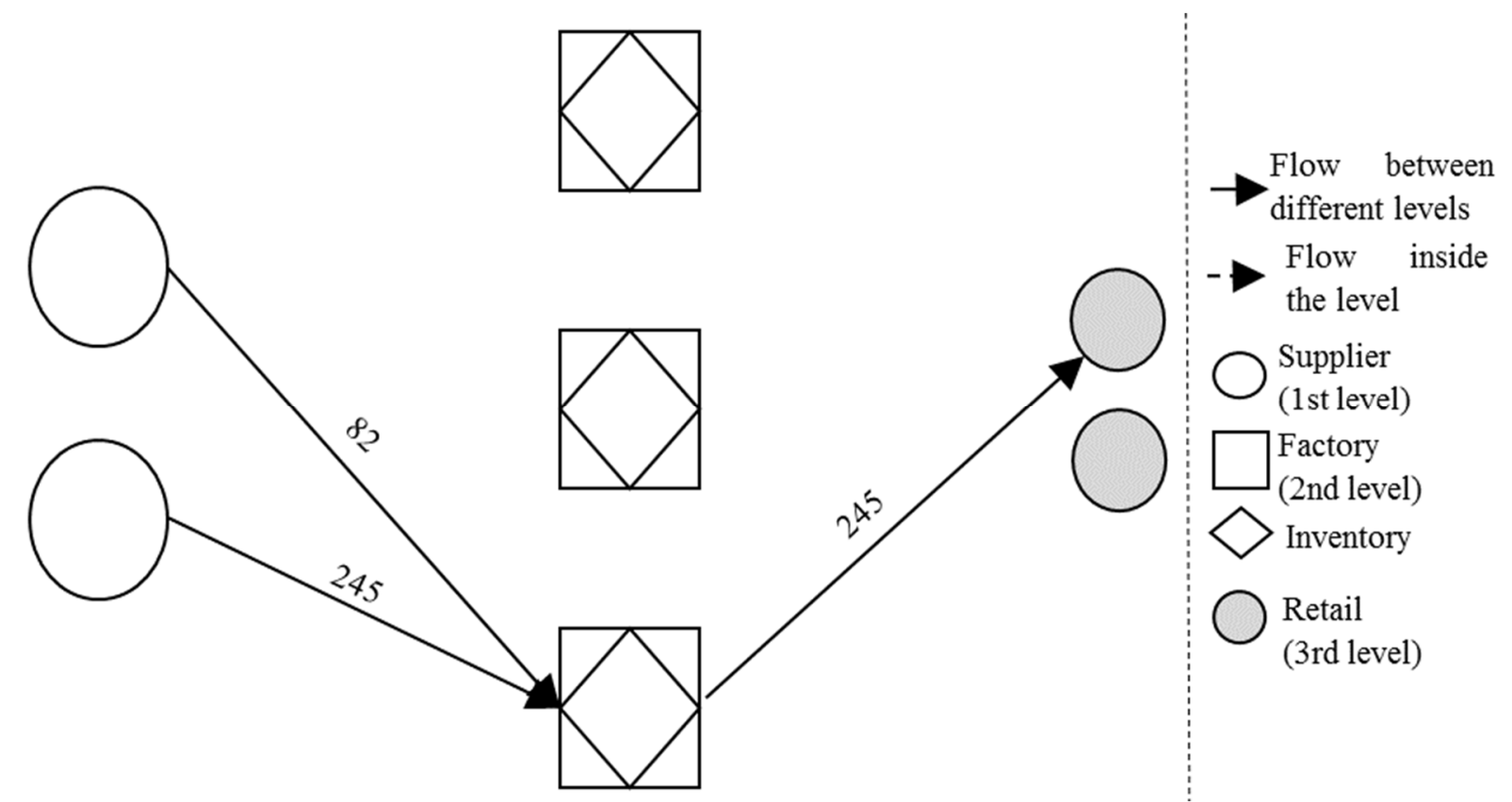

Figure 5. Graphical representation of the solution of Instance 1 


\section{CONCLUSION}

Because of the increasing importance of network costs and use of inventories in business network in supply chain management, this paper presents a mixed integer non-linear programming (MINLP) to solve SCDTP problem.

Moreover, the model supports multiple levels and also considers cost savings associated with combined inventory and production centers. To reduce the complexity of the proposed MINLP model, the model is linearized by defining a new variable and adding a constraint to the model. To solve the proposed model, it was used a commercial solver, the CPLEX 12.5 (IBM, 2012), to find the instance exact solutions. The performance of the software was compared to different sizes of instances.

In some cases, commercial solvers such as CPLEX 12.5 (IBM, 2012), are able to solve the problem in a reasonable computational time, considering the complexity of the important decision to be taken. However, for large problems, there is a need for specific heuristics or metaheuristics, for the CPLEX was not able to finish the solution process, stopping for lack of memory.

Thus, this work presented as a viable tool a model that is able to aid in decision making with fast and optimal answers that sustain a decision making with important information.

Moreover, in the time postponement literature there was no model that presented characteristics like this, which indicated the location of facilities, the centralization of inventories, the quantities transported between these facilities and the cost of the entire supply chain design.

Future research could be aimed at robust models to accommodate the changing parameters of the business environment during the life-time of the supply chain. In addition, addressing the demand uncertainty in a multi-product multi-period supply chains is a promising research way with significant practical relevance.

Moreover, heuristics and metaheuristics, as simulated annealing or genetic algorithm, could be used to solve larger instances. Therefore, these techniques have allowed more suitable solutions to the problem.

\section{ACKNOWLEDGEMENTS}

The authors acknowledge to CAPES (Brazilian Federal Agency for Support and Evaluation of Graduate Education) and FAPES - Project no. 287/2016 - for their financial support.

\section{REFERENCES}

Alderson, W. (1950) Marketing efficiency and the principle of postponement. Cost and profit outlook. v. 3, pp. 15-18.

Aviv, Y.; and A. Federgruen (2001) Design for postponement: A comprehensive characterization of its benefits under unknown demand distributions. Operations Research, v. 49(4), pp. 578-598. DOI: 10.1287/opre.49.4.578.11229

Cardoso, P. A. (2002) The Principle of Postponement: a study at the supply chain of printing inks. Rio de Janeiro: PUC - Pontifícia Universidade Católica. Doctoral dissertation, 161 p. DOI: 10.17771/PUCRio.acad.3752

Çelebi, D. (2015) Inventory control in a centralized distribution network using genetic algorithms: A case study. Computers \& Industrial Engineering, v. 87, pp. 532-539. DOI: 10.1016/j.cie.2015.05.035

Das, C., and R. Tyagi (1997) Role of inventory and transportation costs in determining the optimal degree of centralization. Transportation Research Part E: Logistics and Transportation Review, v. 33(3), p. 171-179. DOI: 10.1016/S13665545(97)00019-7

Eynan, A. (1999) The multi-location inventory centralization problem with first-come, first-served allocation. European Journal of Operational Research, Vol. 114(1), pp. 38-49. DOI: 10.1016/S0377-2217(98)00036-8

Fernandes, B. C.; F. H. Galamba, F. H.; Tosta; L. I. and R. S. Lima (2011) Impactos da utilização de centros de distribuição na logística de distribuição de produtos acabados. Revista de literatura do transporte, v. 5, pp. 163-181.

Ferreira, K. A. (2009) Uma estrutura conceitual para aplicação do postponement: estudo multicaso em empresas da indústria de alimentos. São Carlos: UFSCar - Universidade Federal de São Carlos. Doctoral dissertation, 203 p.

Ferreira, K. A., and R. L. C. Alcantara (2011) Postponement: abordagens para sua aplicação em empresas da indústria de alimentos. In. XXXI Encontro Nacional de Engenharia de Produção, Belo Horizonte, pp 1-14. 
García-Dastugue, S. J. and D. M. Lambert (2007) Interorganizational time-based postponement in the supply chain. Journal of Business Logistics, v. 28(1), pp. 57-81. DOI: 10.1002/j.2158-1592.2007.tb00232.x

Gaur, S.; and A. R. Ravindran (2006) A bi-criteria model for the inventory aggregation problem under risk pooling. Computers \& industrial engineering, v. 51(3), pp. 482-501. DOI: 10.1016/j.cie.2006.08.009

IBM (2012) IBM ILOG CPLEX v12.5: User's manual for CPLEX.

Lau, H. S., and A. H. L. Lau (1996) The newsstand problem: A capacitated multiple-product single-period inventory problem. European Journal of Operational Research, v. 94(1), pp. 29-42. DOI: 10.1016/0377-2217(95)00192-1

Kutanoglu, E.; and D. Lohiya (2008) Integrated inventory and transportation mode selection: A service parts logistics system. Transportation Research Part E: Logistics and Transportation Review, v. 44(5), p. 665-683. DOI: 10.1016/j.tre.2007.02.001

Nozick, L. K., and M. A.Turnquist (2001) Inventory, transportation, service quality and the location of distribution centers. European Journal of Operational Research, v. 129(2), pp. 362-371. DOI: 10.1016/S0377-2217(00)00234-4

Peres, I. T.; H. M. Repolho; R. Martinelli; and N. J. Monteiro (2017) Optimization in inventory-routing problem with planned transshipment: A case study in the retail industry. International Journal of Production Economics, v. 193, p. 748-756. DOI: 10.1016/j.ijpe.2017.09.002

Pishvaee, M. R., Farahani, R. Z., and Dullaert, W (2010). A memetic algorithm for bi-objective integrated foward/reverse logistic network design. Computers \& Operations Research, v. 37, pp. 1100 - 1112. DOI: 10.1016/j.cor.2009.09.018

Razmi, J., A. Zahedi-Anaraki, and M. Zakerinia, M. (2013) A bi-objective stochastic optimization model for reliable warehouse network redesign. Mathematical and Computer Modelling, v. 58(11), pp. 1804-1813. DOI: 10.1016/j.mcm.2013.03.009

Rodrigues, E. F., and N. D. Pizzolato.(2013) The economy of distribution centers: The case of large retail networks in Brazil. African Journal of Business Management, v. 7, pp. 1541-1552. DOI: 10.5897/AJBM2013.1579

Santos, A. (2006) Centros de distribuição como vantagem competitiva. Revista de ciências gerenciais, Vol. 10, pp. 34-40. DOI: 10.17921/1415-6571.2006v10n12p34-40

Servare Junior, M. W. J., G. M. Ribeiro, and G. L. D. Chaves (2012). Um modelo matemático para redes logísticas com fluxos diretos e reversos e novos integrantes. Proceedings of XXXII Encontro Nacional de Engenharia de Produção, ABEPRO, Bento Gonçalves, pp. 1-14. Available in: http://www.abepro.org.br/biblioteca/enegep2012_TN_WIC_162_943_21087.pdf. Access in: 2017 january.

Servare Junior, M. W. J., and P. A. Cardoso (2016) Time postponement in supply chain: a mathematical programming review. Proceedings of 23rd European Management Operations Association Conferece, EUROMA, Trondheim, pp. 1-16.

Alessandri, A., A. Di Febbraro, A. Ferrara and E. Punta (1998) Optimal Control of Freeways via Speed Signalling and Ramp Metering. Control Engineering Practice, v. 6, n. 6, p. 771-780. DOI: 10.1016/S0967-0661(98)00083-5. 